BULLETIN Bulletin hispanique

HISPANIQUE Université Michel de Montaigne Bordeaux

120-1 | 2018

Varia

\title{
El panegírico cristiano novelado según Ordóñez de Ceballos y Jiménez Patón
}

Le panégyrique chrétien romancé selon Ordóñez de Ceballos et Jiménez Patón The fictionalized Christian panegyric according to Ordóñez de Ceballos et Jiménez Patón

Juan Carlos González Maya

\section{(2) OpenEdition}

Journals

Edición electrónica

URL: https://journals.openedition.org/bulletinhispanique/5277

DOI: 10.4000/bulletinhispanique.5277

ISSN: $1775-3821$

Editor

Presses universitaires de Bordeaux

Edición impresa

Fecha de publicación: 30 junio 2018

Paginación: 51-68

ISBN: 979-10-300-0298-0

ISSN: 0007-4640

Referencia electrónica

Juan Carlos González Maya, «El panegírico cristiano novelado según Ordóñez de Ceballos y Jiménez Patón», Bulletin hispanique [En línea], 120-1 | 2018, Publicado el 01 enero 2022, consultado el 08 enero 2022. URL: http://journals.openedition.org/bulletinhispanique/5277 ; DOI: https://doi.org/10.4000/ bulletinhispanique.5277 


\title{
El panegírico cristiano novelado según Ordóñez de Ceballos y Jiménez Patón
}

\author{
Juan Carlos González Maya \\ Universidad Islas Baleares
}

Cet article a pour objet la vision que les humanistes Pedro Ordóñez de Ceballos et Bartolomé Jiménez Patón avaient de la noblesse de Jaén. Il rappelle les principes du panégyrique chrétien et ses points de contact avec d'autres genres littéraires, historiques et rhétoriques de l'époque. Enfin, il identifie la matrice dans laquelle se coule l'éloge.

Mots-clés : Jiménez Patón, Ordóñez de Ceballos, Jaén, éloge de la noblesse.

Este artículo se centra en la visión que de la nobleza giennense tenían los humanistas Pedro Ordóñez de Ceballos et Bartolomé Jiménez Patón. Se repasan las claves del modelo panegírico cristiano y su relación con otros géneros literarios, históricos y retóricos de la época, además de desentrañar el molde encomiástico en el que se basan.

Palabras clave: Jiménez Patón, Ordóñez de Ceballos, Jaén, panegírico de la nobleza.

In this article, I will focus upon the vision the humanists Pedro Ordónez de Ceballos and Bartolomé Jiménez Patón had of Jaen's nobility. I will review the essential components of the Christian panegyric model as well as its relation to other literary, historical and rhetorical genres of the period. Furthermore, I will unravel the matrix in which praise is cast.

Keywords: Jiménez Patón, Ordóńez de Ceballos, Jaén, panegyric. 


\section{INTRODUCCIÓN}

Los estudios y ediciones sobre la obra del célebre gramático y humanista manchego Bartolomé Jiménez Patón (1569-1640) han experimentado durante los últimos años un extraordinario crecimiento, no ajenos a una calidad que con frecuencia ha pasado desapercibida. El descubrimiento de manuscritos perdidos, la edición de textos inéditos o la publicación con criterios filológicos modernos de obras de difícil acceso, nos han redescubierto a un escritor polifacético en su prosa de ideas.

En 2009, se publicó un libro capital para el conocimiento cabal del humanista: Humanismo y Filología en el Siglo de Oro. En torno a la obra inédita de Bartolomé Jiménez Patón, que incluía varias obritas suyas, y en especial su importante tratado de retórica sagrada el Perfecto predicador (1612); y en 2011, Sociedad, pobreza y moda en la España del Siglo de Oro, con edición de sus obras costumbristas tardías, Albergue de pobres (ms. s. xvii), Discurso de la langosta (1619), Reforma de trajes (1638) y Discurso de los tufos, copetes y calvas (1639), ambos a cargo del profesor Abraham Madroñal. En 2010 le tocó el turno al libro decimosexto de los Comentarios de erudición de 1621, a cargo de los profesores M. C. Bosch, J. Garau, A. Madroñal y J. M. Monterrubio, especie de obra completa que pensaba reunir el gramático, y que se creía perdida. Las últimas obras del manchego recuperadas son tres discursos en los que el humanista reflexionaba sobre problemas cruciales de su época, mostrándonos al Patón más radical o intolerante: sus discursos sobre la colocación de la cruz, las plagas de langostas y los estatutos de limpieza, que yo mismo publiqué en 2017 con el título: Discursos (de calamidades, cruces y herejes) ${ }^{1}$.

Dentro, pues, de este marco de recuperación de su obra, voy a presentar algunos apuntes sobre el último texto en el que estoy trabajando. Se trata de la Historia de la antigua y continuada nobleza de la ciudad de Jaén [...] Y de algunos varones famosos, hijos della, impreso en Jaén por Pedro de la Cuesta en 1628. Es un libro misceláneo dividido en dos partes: una sobre hijos ilustres giennenses civiles y religiosos (nobiliario y panegírico) y otra centrada sobre la historia, geografía, costumbres, leyendas y monumentos de la ciudad y diócesis del antiguo Reino de Jaén, posiblemente la parte más atractiva. Se incluyen también capítulos curiosos, como el 39, dedicado a la "honestidad y virtud de las mujeres deste reino y ciudad de Jaén», auténtica rareza en la retratística femenina barroca. Aunque hoy es una obra muy poco conocida, y con escasos ejemplares ${ }^{2}$, su nobiliario y su estudio antropológico-monumental de Jaén, han servido de fuente a posteriores estudios.

1. New York, IDEA, 2017.

2. Existen cuatro ejemplares en la BNE y una edición facsímil preparada por el historiador local Rafael Ortega y Sagrista en 1983. 


\section{Autoría}

Pero antes de centrarnos en el panegírico, vamos a dedicar unas líneas al controvertido asunto de la autoría. Confunde, a primera vista, que el libro se presente en la portada con el solo nombre de Patón al frente cuando se explica en los preliminares, menos en la Aprobación del licenciado Pedro de Arce, que la autoría es doble. Su compañero, don Pedro Ordóñez de Ceballos (c. 1556-1635), al que se cita en varias ocasiones como "primer autor», es un curioso personaje, mezcla entre aventurero, conquistador, historiador, clérigo y escritor. En sus alusiones, Patón lo llama el 'sacerdote-soldado'; y él mismo se define como «historiador, y más católico y sacerdote», recalcando, por un lado, su faceta de analista de la realidad y no de fabulador, aspecto en el que incidiremos más tarde, y, por otro, su lado creyente. Viajero por Europa, Asia y América en diferentes tareas diplomáticas, militares o misioneras, debe su fama al relato de esos episodios en sus conocidos libros de viajes ${ }^{3}$.

Como era costumbre en la época, se dedica el texto a don Alonso de la Cueva, primer marqués de Bedmar, conocido como el cardenal de la Cueva, clérigo y diplomático giennense a cuya casa noble se ofrece el capítulo 31.

En el resto de preliminares no se admite duda sobre la doble paternidad, llegando a concretarse en algún caso la intervención de cada uno. Así lo vemos en el soneto laudatorio de tipo culterano del poeta y catedrático conquense Antonio Martínez de Miota, dirigido «a los autores de la Historia de la ciudad y Reino de Jaén», con que se inicia el libro, donde se detalla esa colaboración en sus dos últimos versos: «[...] que siendo tuya la materia prima / es del culto Patón la forma estrańa.» Acompańa al soneto un epigrama, también encomiástico, en latín, del mismo autor; interesante porque, entre otras consideraciones, pone al descubierto su relación de íntima amistad con el manchego, ambos colegas de profesión ${ }^{4}$, palpable ya desde su primer dístico: «O mihi millenos inter fidissime

3. «Desde edad de nueve años [...] hasta los cuarenta y siete años anduve peregrinando y viendo el mundo» (Viaje del mundo, i, Prólogo, p. 10). Los tres libros donde dejó impresa su memoria aventurera fueron: Viaje del mundo (1614), del que tomó algunos episodios para redactar la Historia de Jaén; Tratado de las relaciones verdaderas de los reinos de la China, Cochinchina y Champáa, y otras cosas notables y varios sucesos, sacadas de sus originales (1628) y Tratado de los reinos orientales y hechos de la reina Maria y de sus antecesores, y tres comedias famosas, una de: "La mejor legisladora y triunfo de la santísima Cruz», y dos del "Español entre todas las naciones». Compuestas por dos aficionados religiosos (1629) (modernizo las grafias, respetando la fonética). En 2008, Raúl Manchón Gómez publicó su biografia: Pedro Ordónéz de Ceballos. Vida y obra de un aventurero que dio vuelta y media al mundo.

4. Auténtico especialista en poemillas introductorios de contemporáneos suyos, encontramos su firma en la Elocuencia española en arte (1604), deshaciéndose en elogios al manchego ( El licenciado Antonio Martínez de Miota», h. 47 del Liber unicus de eloquentia sacra, en Mercuris trimegistus). Recordemos que el Mercurius trimegistus de Patón (Baeza, 1621), probablemente el tratado de retórica más importante de su tiempo, fue libro de texto en numerosas cátedras peninsulares, entre ellas las giennenses (Becerra Hiraldo, 2009: 66-67). Uno daba clases en Villanueva de los Infantes (Ciudad Real) y otro en el Colegio de Santa Caterina, en Cuenca. 
amicos» (‘ $¡ \mathrm{Oh}$, mi más fiel entre miles de amigos’), acompañado de otras expresiones ponderativas. Pero lo que nos interesa es una nueva mención a la autoría en los versos 13-14, donde vuelve a confirmar los papeles de cada uno como ya mostrara en el soneto: «Esas historias que el trotamundos Ordóñez inició en otro tiempo, / tú las has narrado con mayor perfección.»

El siguiente preliminar, una dedicatoria del hijo del humanista, don Félix Patón y Monsalve, al marqués de Bedmar, podría confirmar la estrecha relación entre los autores hacia 1628, antes de que padre e hijo rompieran sus relaciones ${ }^{5}$; incide sobre la consabida doble paternidad: "Que un padre engendre dos y más hijos a nadie causó maravilla, mas que un hijo lo sea de dos padres opone admiración al entendimiento humano.»

En el prólogo "Al lector», es el propio don Bartolomé quien explica el proceso de incorporación al proyecto. Cuenta el interés que tenía en conocer a Ordóñez, después de leer su obra, cómo fue a parar a sus manos un libro inacabado, en principio extraño a sus materias, y cuál fue su dedicación: «Para que no te canses, letor, en adivinar el porqué la obra prometida y comenzada por otro la haya proseguido yo y dádole el fin que he podido, contaré el suceso cómo pasa.» Ese "porqué» es el que refiere en el siguiente prólogo-carta dirigido al primer autor fechado en 1616, doce ańos antes de la publicación, cuando Patón era notario apostólico de la Curia Romana y notario del Santo Oficio de la Inquisición de Murcia.

Por la lectura de esta correspondencia, que el manchego tiene la honradez y el acierto de incluir, conocemos cómo nació el interés de colaboración entre dos ingenios que todavía no se conocían aunque se admirasen mutuamente («conocile por su fama al que ignoraba con la vista», manifiesta Patón) ${ }^{6}$. Ordóñez le comunica inicialmente que tiene varado el libro por dos motivos: el primero, "la envidia de los ánimos» de sus paisanos, sin concretar, que «casi me hiciera detener en ello, mas esta con algunas consideraciones la he vencido» ${ }^{7}$, razón por la cual se podría explicar la ausencia de su nombre en la portada. El andaluz era un absoluto desconocido en el mundo de las letras hasta que en 1614 publicó dos títulos: Cuarenta triunfos de la Santísima Cruz de Cristo N.S. y Maestro y Viaje del mundo. Con la primera obra no tuvo dificultades y fue texto que gustó mucho a Patón, como recordaremos más tarde; pero la segunda, por lo visto, fue duramente criticada por fantasiosa e inverosímil y ridiculizada incluso en el siglo siguiente por el padre Isla, como recuerda Martínez de Mazas ${ }^{8}$, a pesar de contar con varias ediciones en pocos ańos y

5. Madroñal, 2011: 13-14.

6. También a las mismas líneas corresponde este trato tan apasionado: «le amo, estimo, venero y ansiosamente deseo conocer con mi vista por más justas causas».

7. Tema este recurrente en otras obras suyas, iniciadas con quejas a sus murmuradores que le lleva incluso a buscar el amparo de algún santo o virgen.

8. Según Mazas llegó a ser censurado de 'viajero mentiroso'; además, «padeció varias censuras poco benignas» (1794: 9). 
traducciones al latín, holandés y francés entre 1621-22 ${ }^{9}$ Y aun hoy en día todavía cuenta con detractores ${ }^{10}$.

Este y no otro, creemos, fue el motivo verdadero que le llevó a ofrecer su trabajo a alguien más preparado. Es posible que Patón mostrara sensibilidad hacia el asunto y no dudó en echarle una mano al amigo, por lo que, indirectamente, su incorporación al proyecto también buscaba la rehabilitación del nombre o la fama de Ceballos. Las cinco comedias escritas sobre las hazañas del andaluz entre 1628 y 1634, también abundarían en la misma dirección ${ }^{11}$.

El segundo motivo, presentado como más relevante, una penosa enfermedad que, según leemos en la biografía de Patón (cap. 37), llegó a tenerlo postrado más de diez meses en cama sin poder levantarse ${ }^{12}$. Parece no resultar esta una afirmación gratuita, ya que sabemos por varios testimonios que a la vuelta de América, a principios del siglo XVII, su salud se resintió seriamente; y que los últimos años de su vida también los pasó sin poder salir de su aposento ${ }^{13}$.

Dado el interés en dar a la luz su obra y de que el Maestro de Villanueva de los Infantes era entonces un hombre culto y considerado y que se mostraba predispuesto, le envía carta fechada en Jaén, a 30 de septiembre de 1616, adjuntando el borrador de sus escritos, solicitándole esencialmente que acabara y completara el libro y que puliese su estilo: «tome esta obra por su cuenta y así en acaballa como en perficionar lo hecho ponga algún trabajo honrando el mío.» El manchego parece mostrarse abrumado por el encargo, pero acepta el reto «más con deseo de agradar que con esperanzas de dalle la perfeción que la obra y principios piden", e incluso le adjudica el rimbombante título de Doce maravillas y doce famosos hijos de la ciudad de Jaén, excluyendo las genealogías que, dice, serían motivo de un segundo libro, incidiendo en su interés: «la quiero tomar -la Historia de Jaén- para dilatarla en lo que me fuere posible» (Preliminares sin numerar).

A pesar de estas consideraciones sobre la génesis del libro, expresadas con tanto detalle, todavía resulta sorprendente entender por qué se pudieron cruzar

9. Zugasti, 2003: 89. Además, entre 1628-34 se compusieron cinco comedias sobre sus hazañas o viajes, dos de Alonso Remón, una de fray Francisco de Guadarrama y dos anónimas. Según Zugasti este no es un hecho casual sino que responde a un teatro de encargo sufragado por él mismo o algún benefactor, como parte de una campaña de promoción (p. 92). Lo cual vendría a coincidir con los propósitos de nuestra Historia de Jaén.

10. Serrano y Sanz, 1905: xcii-xciv; Jos, 1943, p. 15; Anzoátegui, 1947:12. Juan L. Alborg dice: «No cabe duda de que algunos de los episodios contados por Ordóńez son sospechosos en sí mismos» (1957: 75-76).

11. Ver nota 9.

12. Patón, en cambio, en su Prólogo al lector, achaca más a «la fuerza de los envidiosos» que a la «poca salud» los problemas por los que pasó su solicitante. Y en su Prólogo-carta, que viene a ser una defensa de su amigo y todo un tratado sobre la envidia, llega a afirmar que «las murmuraciones de los que hoy viven no me inquietan, que unos por amor y otros por odio, te apartan de lo justo». Además, a diferencia de sus murmuradores contemporáneos, él sí que cree todo lo que escribió su amigo, lo cual podría explicar también las vacilaciones en la autoría del libro.

13. Zugasti, 2003: 91. 
los caminos de ingenios y proyectos tan dispares. ¿Fue realmente la admiración de un autor consagrado hacia otro novel o casi desconocido? La colaboración entre dos o más autores era habitual en el teatro de la época, pero más rara en prosa. Además, después de lo que hemos podido leer, la calidad literaria del giennense, a pesar de lo que manifiesta su colaborador-corrector, no era extraordinaria; Patón, en cambio, en 1616 ya había publicado sus importantes obras filológicas y retóricas. Sin embargo, ambos tenían en común algo que les unía poderosamente: su profunda devoción religiosa ${ }^{14} \mathrm{y}$, en especial, su fervor por los triunfos de la Santísima Cruz ${ }^{15}$. Por ello no sería descabellado pensar en la huella que ejerció en el manchego la publicación por esos años de los Cuarenta triunfos de la Santísima Cruz de Cristo N.S. y Maestro (1614), de Ordóñez de Ceballos, obra que no deja de alabar en su Prólogo-carta, y que fue una de las fuentes de su Decente colocación de la Santa Cruz (1635), uno de los tratados de cruce más conocidos de su tiempo, con una introducción laudatoria del propio Ceballos donde este se enorgullece de la «comunicación familiar que entre los dos tenemos» ${ }^{16}$. Ya en 1628, en la dedicatoria de su Tratado de las relaciones verdaderas de los reinos de la China, Cochinchina y Champaa, y otras cosas notables, lo considera "el mayor amigo mío» ${ }^{17}$. Los elogios mutuos, nacidos a partir de su primera colaboración en 1616, y continuados en los prólogos de diferentes obras, nos indican la buena sintonía que caracterizó sus relaciones, y que llega como mínimo hasta 1628.

Del encargo inicial deducimos, en primer lugar, un interés por el estilo manifestado por «el Autor primero desta obra», a pesar de que el corrector le contesta que "le hallo a todo muy buen lugar", e incluso se atreviera a equipararlo con San Pablo ${ }^{18}$. Por lo que esta preocupación por el estilo no vendría a ser más que un intento de disfrazar un texto atenazado por las envidias, para presentarlo en sociedad bajo un nombre de autor consagrado. Lo cual nos lleva a una segunda consideración, que confirma el prestigio o la fama de que gozaba el manchego por esos años, antes de que empezara a tener dificultades para imprimir su obra ${ }^{19}$.

Hoy en día ya nadie discute la doble autoría del libro, sin embargo todavía quedan dudas sobre la participación de los progenitores. En este sentido, la

14. Patón escribió un apasionado Discurso en favor del santo y loable estatuto de la limpieza, publicado en 1638, que representa una muestra más de su preocupación por la unidad de la fe. Estamos preparando una edición de este texto que pronto verá la luz.

15. «de quien yo he sido y soy muy devoto» (Patón, Prólogo al lector). Cada vez que tiene oportunidad de recordarla, lo hace con carińo: «... estimo como mío, porque en las victorias deste árbol sagrado hizo la estrena mi pluma los años de mi juventud» (Prólogo-carta a Ordóńez).

16. Decente colocación de la Santa Cruz, h. 6.

17. Jaén, Pedro de la Cuesta, 1628, f. A3.

18. El Apóstol por excelencia para Patón (Elocuencia española en arte, p. 262), y fuente de inspiración de numerosos escritos suyos: «No soy amigo de lisonjas, más soylo de dar a cada uno la verdadera alabanza, porque con ella la virtud crece, y así digo con sencillo sentimiento que hallo en v.m. mucho de imitación de San Pablo» (preliminares sin numerar). Para Garau-Bosch, la fe de Patón es de inspiración paulina (2014b: 49).

19. Madrońal, 2011:14. 
crítica está dividida. Los hay que consideran que la redacción íntegra y la mayor parte de su contenido, especialmente la más interesante, pertenece a Patón, quien, a su vez, se sirvió de los borradores de su amigo ${ }^{20}$; los hay, en cambio, que adjudican a este el papel de mero arreglador $\mathrm{u}$ ordenador ${ }^{21}$. En cualquier caso, nos encontramos ante un narrador omnipresente, que aparece bien como "historiador cristiano», bien como cronista, conquistador o sacerdote, a menudo preocupado por la verdad histórica, certificando la veracidad de lo que cuenta a cada paso. Es este un recurso característico de los cronistas de Indias, pero que aquí tiene otra lectura, debido posiblemente a las críticas que recibió su Viaje del mundo: "que a fe de historiador verdadero, con las obligaciones de cristiano sacerdote, certifico que...» (fol. 114). Puede que en estos casos hubiera correcciones de estilo por parte de Patón, pero el empeño en no pasar como mentiroso pertenece a Ceballos.

En otros casos, en cambio, resulta más problemático rastrear la autoría. Solo después de un minucioso estudio del estilo podríamos aventurar algunas conclusiones que ahora se pueden adelantar.

Ya hemos visto cómo en el cruce de correspondencia y en las poesías preliminares se deja bien claro que el libro está escrito por Ordóñez de Ceballos, y que el trabajo de Patón se ciñó a corregir cuestiones de estilo y a desarrollar algunas historias incompletas. Pero dado que entre las cartas y la publicación pasaron doce años, el manchego tuvo tiempo suficiente para enmendar los errores, ańadir capítulos de su cosecha y, desde luego, actualizar acontecimientos. La última fecha que leemos es la de agosto de 1627 (fol. 174), a propósito de un nombramiento de los condes de Quesada, tres años después de los preliminares, y a solo unos meses de las erratas de mayo de 1628 y de la tasa de agosto del mismo año.

En general, las actualizaciones se centran en acontecimientos posteriores a la correspondencia comentada de $1616^{22}$, normalmente nombramientos de obispos u otras jerarquías eclesiásticas, o tomas de posesión en casas nobles; pero también en la inclusión de una extensa biografía del primer autor, cerrada entre los preliminares más tempranos del libro (junio de 1624) y mayo de 1628 (Ordóńez murió en 1635) ${ }^{23}$; o de acontecimientos políticos como la entrada de Felipe iv en Jaén el 11 de abril de 1624 (fol. 199). En general, es

\footnotetext{
20. Ortega y Sagrista, 1983: prólogo sin numerar.

21. Martínez de Mazas: «No se sabe lo que añadió de su ingenio ni lo que es legítimamente de Ordóńez, pero se conoce fácilmente que todo o lo más es de este, así por el estilo como por la bondad de su genio y por su amor a la Patria» (1794:10-11); Montuno Morente (1945: 345-47) es de la misma opinión.

22. Lo cual demuestra que estaba bien informado de lo que sucedía en tierras giennenses, bien por sus viajes cuando su primogénito profesaba en Baeza o porque algún conocido le tenía al corriente.

23. Cap. 37: «Del famoso soldado y sacerdote don Pedro Ordóńez de Ceballos, primer auctor desta historia», fols. 201-215v. Añade Patón en sus palabras iniciales que la fama del autor es tan grande, "que estarán muchos con deseo de saber el estado que hoy tienen sus cosas y algunos sucesos que de industria pasó por alto y sonarán mejor repetidos de boca y pluma ajena, aunque sea la mía, que de la propia» (fol. 202 v.).
} 
fácil advertir estas intromisiones porque es el mismo Patón quien facilita las fechas: «...Y ahora de nuevo el señor rey don Felipe Cuarto, nuestro señor, los confirmó este año de 1627» (fol. 199). Lo cual demuestra que, al menos hasta agosto de 1627 (fol. 174), estuvo ocupado en la conclusión del libro.

Pero no solo se encuentran actualizaciones en las intervenciones del manchego. Las adiciones también pueden venir por los paralelismos con su estimado Campo de Montiel, por las innumerables reflexiones de tipo moral ${ }^{24}$ o la inclusión de esa suerte de erudición acumulativa tan característica de su obra. Es ahí, sobre todo, donde se advierten las marcas habituales de su expresión en la complicada sintaxis donde los períodos se retuercen y llegan a su barroquismo pleno con oraciones cargadas de saber, especialmente de citas del Antiguo Testamento y la Patrística ${ }^{25}$, y con periodos interminables desviados continuamente por los incisos, a veces de varias páginas ${ }^{26}$, las reformulaciones o los ejemplos, como veremos más adelante; pero también en los paralelismos ponderativos de los encomiados con personajes famosos; y en el estilo sentencioso, abundantísimo, de orientación virtuosa o religiosa (con citas: "porque la mayor ciencia es conocerse a sí mismo Nescere ipsum, la mayor fortaleza es vencerse Fortior est, qui se quam qui fortissima vincit» -Proverbios, 16, 32, sin mencionar-; sin citas: «La virtud obliga al amor de aquellos que jamás vimos tomando por instrumento las lenguas de la fama»). Al tiempo que gusta de dirigirse al lector con sus exhortaciones admonitorias: «Repara en esto, lector cristiano, y tú que, como dicen por quita allá las pajas, sueles jurar y perjurar; y atiende que es un vicio ocioso y vano que ha de traer a tu casa grandes desventuras.» Así, pues, Patón remató el libro, lo puso al día y corrigió su estilo. De su pluma es ese tono predicativo tan característico de su obra.

En definitiva, podemos concluir en que el proyecto fue alumbrado por Pedro Ordóńez de Ceballos, quien redactó la mayor parte de su libro; que por motivos de enfermedad, y en carta fechada el 30 de septiembre de 1616, cuando ya tenía bastante avanzada su redacción, solicitó la colaboración de Jiménez Patón, a quien debemos los últimos capítulos (del 37 al 46), con el inicio de la biografía de su amigo. Este a su vez, no oculta su mano con algunas alusiones a su intervención.

Todos los ejemplos anteriores nos llevan a reflexionar también sobre la importancia del autor quien a veces toma la piel de cronista, otras la de clérigo o filósofo y otras la de panegirista, haciéndose notar en casi cada página, engarzando con su presencia todas las historias: «Aquí dejo de contar... solo digo que..." (fol. 120); "No es mi intención hacer comparación porque cualquiera es odiosa, ni mi ánimo escurecer la fama de unos, celebrando la de los otros» (fol. 128). Lo vemos como colofón de algún retrato, exhortando al

24. El moralismo es una de las peculiaridades de su obra, quizá debido a su intensa labor pedagógica.

25. Más visible todavía en los retratos de los hombres de religión y obispos.

26. Al final de una digresión, es frecuente encontrarse con apelaciones del tipo: «Alguno me preguntará a qué propósito hago esta digresión». 
lector con reflexiones edificantes: "Compungido, y con razón, estarás lector amigo, y plega a Dios quedásemos todos edificados con las heroicas virtudes, vidas milagrosas de los sacerdotes que he referido" (fol. 98v); otras aconsejando, «lee con piadoso afecto» (fol. 99); otras, confirmando la veracidad de lo contado, con señalamiento incluso de fuentes orales o escritas: «Y certifico que he visto otros muchos papeles del linaje de los Aranda, cuyo legítimo sucesor y descendiente por vía masculina es Bartolomé de Aranda, hijo de padres muy nobles y muy cristianos» (fol. 99v); "y capitanes de los que en ellos se hallaron me certificaron que si no fuera por él...» (fol. 120); reproduciendo supuestas conversaciones que el narrador recuerda de memoria; o acudiendo a tópicos variados sobre los finales de las narraciones: «y si los hechos de ... [familiares los Benavides] los hubiera de referir, fuera no querer poner fin a mi historia, solo se tenga por cierto que los unos y los otros sirvieron a la cesárea Majestad del Emperador Carlos Quinto, que ningunos más valientes, ningunos más leales, ni cuidadosos en las cosas de su obligación y oficio» (fol. 127v)... De forma que a veces tenemos impresión de que el verdadero protagonista de los retratos es la capacidad evocativa del yo cronista, convertido en ¿involuntario? eje central de lo que él mismo define como «MI HISTORIA».

\section{GÉNERO}

Esta importancia del narrador nos llevaría a una segunda consideración que nos conduce al género de la obra. En ese reconocimiento público que busca para sus egregios protagonistas, los autores manejaron diferentes fuentes y técnicas que, aunque conocidas por la tradición, juntas podían aportar novedad. La obra, en ese sentido, recibe la influencia de varias tradiciones que confluyen en la narración y que, de alguna manera, la definen, aunque sus objetivos no sean intrínsecamente literarios. Como fuentes de inspiración se rastrean motivos de los panegíricos clásicos, las hagiografías, las crónicas de Indias y los libros de caballerías; y como técnicas, las citas eruditas, propias de la corriente humanística, las relaciones o informes a la Corona y las habilidades narrativas. Este último aspecto, desvinculado de la exposición objetiva de los hechos, lo acerca a los libros de caballerías por cuanto resulta vehículo ideal para exaltar los valores heroicos de la aristocracia. La sucesión, a veces acumulación desordenada, de lances o episodios muchos de ellos fantásticos o exagerados por el arrojo de los protagonistas, nos retrotrae a ese tipo de literatura; pero también a las crónicas de Indias, por lo que resulta natural que algunos investigadores hayan puesto en duda su fidelidad histórica en múltiples ocasiones ${ }^{27}$.

Este asunto de la verdad histórica, en el que inciden varias veces los autores, con la inclusión de testimonios escritos y orales, tenía entonces principalmente que ver con el recuerdo, con la evocación; pero al mismo tiempo, se relacionaba

27. Ver supra nota 9. 
con la tradición, respondiendo así a una mezcla entre el texto historiográfico humanista (historia, retórica y erudición), la tradición historiográfica clásica y la tradición mítica, al estilo de Herodoto, quien mezclaba tanto lo verosímil como lo inverosímil. Veamos este ejemplo:

Los cuales, encontrándose a ser socorridos del otro, se desbarataron unos a otros, y dando los nuestros voces de vitoria, vitoria por España, fueron en su alcance y degollaron aquel día más de cinco mil dellos, y no faltaron de los nuestros sino muy pocos. Donde después de haber sido los autores de todo nuestros Ordóńez y Berrio, se señalaron con tanta ventaja él y su camarada Peláez, que mandó el Conde les diesen el quinto del despojo (fols. 125r-v).

La naturalidad con que se cuentan estos hiperbólicos sucesos sangrientos, y otros más semejantes a lo largo de todo el libro, nos remite a las truculentas descripciones del Padre Bartolomé de las Casas en sus obras y, en especial, a su famosa y polémica Brevisima relación de la destruición de las Indias, pero en sentido inverso. Si en la obra del dominico este se ponía sistemáticamente de lado del más débil, en la nuestra es el poderoso quien acaba con todo tipo de resistencia, indígena o militar, europea, americana o asiática. Pero también nos remite a esa lectura edificante o providencialista, tan consustancial a ese tipo de relatos, de raigambre medieval, quizás a modo de exemplum para los lectores: «... Ordóńez le estaba diciendo ríndete o te mataré, y él respondió: 'Yo me rindo. Déjame, no me mates hasta haberme hecho cristiano, porque Dios me inspira con nuevos favores y auxilios. Lo que me importa es serlo para vivir en la gloria que confieso ser vuestra religión católica, la verdadera; y sin mezcla de engaño ni falsedad, bautízame, bautízame’» (fol. 210). De forma, que del género crónicas, ya en decadencia en la época de redacción del libro, podría haber tomado, además de lo mencionado, el yo cronista, aquí no autobiográfico, observador de la realidad: la visión providencialista; la admiración por el heroísmo de los caballeros; la mezcla de historia y épica, de realidad y ficción; los testimonios ajenos (cartas, informes, conversaciones...); el relato o recuerdo de sucesos extraordinarios, insólitos ${ }^{28}$; y el deseo de perpetuar la fama.

Pero volviendo a la técnica narrativa, observamos que, aunque los autores transitan por el orden clásico de exordio, narración y epílogo, sus retratos se centran especialmente en episodios aislados, en sucesos extraordinarios, no en una sucesión cronológica biografiada sino en un seguido de hechos fabulosos, que prueban el valor o el arrojo de los biografiados como motivo central, omitiendo todo hecho no decoroso. La presencia femenina, como es de esperar en este tipo de textos, desaparece por completo. Por otro lado, la aparición del autor en primera persona, al modo del yo cronista, sirve también para incidir en su conocimiento, ya que su personalidad aflora continuamente con sus observaciones o experiencias.

28. Para Cicerón, muy apreciado entre los humanistas, la historia es el recuerdo de los grandes hechos. Y así lo recoge Ceballos en su Viaje del mundo: «Y el príncipe de la elocuencia, Cicerón, alaba las historias con grandiosos nombres» (Prólogo al lector). 


\section{LA EPIDÍCTICA CRISTIANA: HISTORIA Y RETÓRICA}

Más de la mitad del libro se dedica a cantar las vidas ejemplares de ilustres varones del Reino de Jaén, pasados y recientes, clérigos y seglares. Y aquí entramos ya de lleno en el motivo central de estos apuntes: el género encomiástico, demostrativo o epidíctico entre los géneros de causa de la retórica clásica.

Es este un tipo de discurso, en prosa o verso, de raíces clásicas, especialmente latinas, pero también humanistas. Por su cercanía en el tiempo, es posible que el tándem de autores tuviera presente, entre otros, el modelo de los Elogios o vidas breves de los caballeros antiguos y modernos, ilustres en valor de guerra, del historiador, humanista y obispo Paulo Jovio (o Giovio), traducidos por Gaspar de Baeza en 1568. Comparten con el italiano idéntica finalidad, estructura y procedimientos retóricos; en cambio, les separan la intención crítica: no se encuentran vituperios de personajes famosos en nuestro libro. No obstante, permanece ese relato aventurero de personajes guiados por la gloria hacia conquistas o exploraciones varias que perpetuaran su fama.

Tiene la Historia de Jaén también unos parientes limítrofes que exaltan igualmente a la aristocracia áurea, como los elogios fúnebres ${ }^{29}$, los epitalamios, la epopeya, la poesía heroica... con los que se cruza compartiendo propósitos y algunos recursos; pero que en nuestro caso, por la afiliación religiosa de los autores e intenciones y el dominio de la elocuencia sacra por parte de Jiménez Patón, los caminos de nuestra laudatio convergen más con la tradición hagiográfica en prosa, de tópica especial, constituyendo género propio: el panegírico cristiano no santoral, alejado del verso y de la intención culta al estilo del Panegírico al duque de Lerma, de Góngora (1617), y de amplia repercusión en las letras de su tiempo. Comparte, pues, con las vidas de santos tres motivos esenciales en este tipo de discursos: la exaltación de la gloria de un personaje ilustre, generalmente ya fallecido; su lectura ejemplarizante como motivo edificativo, cristiano, privilegiando el énfasis tanto en la forma como en el contenido; y la narración de algunos milagros por intercesión divina ${ }^{30}$. De la lectura de estos retratos, se desprende el talante conservador de unos escritores aferrados todavía a los valores imperiales de una España triunfante en la fe y en lo militar, enfoque que se distancia de otros contemporáneos suyos, como Quevedo, censores de un país en decadencia.

Así, pues, nuestros autores transitan por un cauce creativo de larga tradición en sus encomios, que con el tiempo se ha ido adaptando a los diferentes estilos. Este planteamiento genérico y sus evidentes relaciones con la Retórica

29. Se podrían incluir en el grupo las oraciones fúnebres de Paravicino, estudiadas admirablemente por F. Cerdan (1985: 78-102).

30. "Apareció un Cristo crucificado entre las almenas del muro y les habló a los changuayes diciéndoles: gente maldita, ¿por qué afligís mi pueblo? Viéronles dellos infinitos y le oyeron. Y así dejaron el asalto y se dividieron en tres ejércitos, y fueron a destruir los pueblos comarcanos» (fol. $111 \mathrm{v})$. 
y la Historia, nos hace tomar con precaución su grado de aproximación a las fuentes documentales, porque aunque las notas de tipo histórico y las encomiadas se crucen en numerosas ocasiones, el enfoque de estas últimas suele ser peculiar: la hipérbole epidíctica, la eliminación de cualquier asomo de crítica, la amplificatio y, posiblemente, algún falseamiento, colocan nuestros retratos en un territorio intermedio entre la ficción y la realidad, como hemos comentado líneas más arriba. Es cierto que estos aportan valor documental y que contextualizan épocas, episodios o personajes, pero dependen de múltiples factores y no solo históricos, circunstancias ligadas a diferentes motivos de la creación y de la tradición que van acompañadas de no pocas dosis de parcialidad y de una inquebrantable fe religiosa.

El arte retórico constituye el cauce idóneo para el tratamiento de los encomios de los hijos ilustres de Jaén. Y, en este sentido, se nota que los autores no tomaron derroteros distintos a los preceptos aristotélicos o de Quintiliano, que el mismo Patón refrendó en su Elocuencia española en arte, donde, además, insistía en una narración aleccionadora ${ }^{31}$. Y, dado sus relaciones con el arte cristiano, deberíamos añadir también la estructura sermonística y pedagógica, vía habitual de otras obras piadosas del manchego que dan fe de su religiosidad, como el Perfecto predicador (1612) ${ }^{32}$. Hombre de enseńanza en diferentes localidades y catedrático de Elocuencia, se adaptó así en intención y forma a la nueva España contrarreformista y tridentina.

Pero, ¿cómo se manifiesta todo este gusto? Tomaremos como ejemplo el caso de don Fernando de Torres y Portugal, conde de Villardompardo y virrey de Perú entre 1585 y 1589 (cap. 26), prototipo del gobernador cristiano. Como la alabanza a menudo suele tener un fin práctico y se sustenta en las pruebas para justificar los hechos, se busca esta, sobre todo, en las virtudes militares ${ }^{33}$, en la justicia y en la devoción cristiana como síntesis del gobernante ideal. Los rasgos inherentes a estos principios giraban en torno a las virtudes que debe guardar todo buen cristiano: la justicia («satisfacía quejas y agravios de los pobres»), la honestidad («Por esta causa los escribanos, alguaciles, alcaides, corchetes y otros ministros de justicia no estaban agradados de su gobierno, porque les quitaba las ocasiones de robar a los pobres»), la devoción o fe («Encomendaba sus acciones a Dios [...] No se le pasó día ninguno sin oír misa con mucha devoción»), la caridad (procuraba grandes limosnas a conventos y cárceles), la fortaleza («más buen gobierno es el que menos castiga, porque tiene refrenadas las causas de los delitos»), la defensa de los indios, bajo cuyo mandato fue "creciendo el número de los fieles y acrecentándose la iglesia católica»... En este asunto, los autores adoptan una postura crítica contra los excesos de algunos conquistadores o predicadores, cuando, por ejemplo, el Conde envía a predicar

31. «La narración se inventó para enseñar y avisar» (Elocuencia española en arte, p. 363).

32. Editado por A. Madroñal, 2009: 191-276.

33. De evidente paralelismo con la noción cristiana de la vida como milicia, de regusto militar. 
el Evangelio a personas "no codiciosas del dinero»" ${ }^{34}$. El tema de la corrupción, de larga trayectoria social y literaria y flagelo de la Corona, irrumpe también en las pinturas para mostrar la integridad de los elogiados: al volver a España, «ni a él ni a sus hijos se les ha parecido acrecentamiento de haciendas sino la gloria del buen nombre que vale más que muchas dellas». Culmina la labor encomiástica con la imagen del buen gobernante, amado tanto de sus súbditos como de sus contrarios o rivales. Es el tópico clásico de omnis sexus et aetas: «En todo se parecía ser el gobierno del príncipe pacífico, cristiano, religioso, piadoso y devoto Salomón español, Numa católico, porque todos los estados de aquellos reinos no acababan de alaballe y deseaban fuera su gobierno perpetuo.»

Este molde genérico epidíctico, aquí cristiano, abarca lógicamente otras parcelas que son características inherentes a su función práctica. Y esta la encontramos relacionada con la crisis del imperialismo espańol y de toda la sociedad durante el reinado del tercer Felipe, al tiempo que paradójicamente florecen las artes. Esta sabida contradicción más el molde genérico e ideológico está en la base de las diferentes alternativas sugeridas.

$\mathrm{Si}$, por un lado, surge la queja o la crítica, que nace de un sector de población descontento o maltratado por la crisis, que tiene su traducción en forma de sátira social o política ${ }^{35}$, es decir, en ataque a los gobernantes; por otro, también se produce la alabanza a ese mismo estamento por diferentes motivos, que se atestiguan en los igualmente abundantes encomios o panegíricos, en aras a su prestigio o consideración social. Lo cual pone al descubierto, una vez más, las estrechas relaciones entre la clase dirigente y la creación literaria, motivo ampliamente estudiado por la crítica.

En cualquier caso, estas intenciones pueden explicarse por factores extraliterarios, ideológicos o político-sociales, que convendría examinar en su momento. La irritación popular se podía canalizar, así, por medio de la sátira sobre todo, pero también a través de la creación de mitos, fórmula esta de probada eficacia. En este caso se trataría de mitos no surgidos del pueblo sino de la clase dirigente, por tanto, en absoluta connivencia con el sistema político en el que nacen, por lo que podríamos entender que este tipo de composiciones se presentan como resultado de un proceso de celebración o enaltecimiento de una élite con un peso político-social considerable que defiende su status en su particular cursus honorum ${ }^{36}$.

34. Es constante en el libro, en los personajes que estuvieron en contacto con América, la defensa del indígena. En algunos casos, incluso, se deja constancia de algunos excesos, siguiendo la estela de algunas crónicas críticas con la conquista. A propósito de Espinosa de los Monteros, "No ha castigado soldado Castilla si no es por traición o por maltratar los indios».

35. Muy abundante en los reinados de los Austrias menores (Etreros, 1983:16).

36. Para consideraciones sobre la nobleza en el Antiguo Régimen, resulta imprescindible la lectura de uno de los clásicos de nuestra historiografía moderna: Antonio Domínguez Ortiz, 1963, La sociedad española en el siglo xvii. i. El estamento nobiliario. 


\section{Paradigmas ENCOMiásticos}

El cauce expresivo del encomio, con algunos moldes anquilosados que remiten a la creación de conocidos «topos» o fórmulas de tono apologético, está íntimamente ligado a la materia tratada. Esta, según la inventio clásica, debía responder a una serie de loci a persona que, en nuestros retratos, son: familia, nación, ciudad, edad, educación, fortuna, condición social y carácter, que se podrían resumir en los siguientes tres: virtus militaris, personales y religiosos del héroe, de donde provienen fundamentalmente los argumentos. Con ello llegamos a los tópicos tradicionales de persona, especialmente los vinculados al elogio personal epidíctico: el sobrepujamiento ${ }^{37}$, tópico muy ligado a las expresiones ponderativas (Alejandro, sobre todo; Marcial, Colón, Salomón, Roma...), de larga vida entre los escritores humanistas que, en algunos casos, también se aprovecha para hechos históricos; la nobleza del alma o del espíritu, que se nota sobre todo en las hazañas militares con el trato o la admiración de los vencidos o en el cariño permanente de sus súbditos; la fama de sus acciones, coronada por los sucesivos elogios de los monarcas o altos dignatarios; los dones con que la naturaleza o la divinidad, permanentemente recordada, ha sabido distinguir al encomiado; en algunos casos, la humilitas cristiana («y aunque el regimiento le nombró por capitán, no lo quiso aceptar diciendo que él iría como el más mínimo soldado sirviendo a su Dios y Rey»); la obediencia; $\mathrm{y}$, especialmente, sapientia et fortitudo, para explicar el lustre de los egregios personajes, que aúnan en sus retratos las cualidades del buen cristiano con las del perfecto soldado.

Por otro lado, junto al carácter intencional ya mencionado, debemos considerar ciertos rasgos técnicos inherentes al género panegírico que son los que le han dado forma literaria. Y es aquí donde se nota más la mano de Jiménez Patón, escritor ya curtido en la época de redacción y de larga trayectoria filológica.

La importancia del lenguaje hiperbólico es inherente a la misma naturaleza del género. El ennoblecimiento y la sublimación que los laudatorios hacen de determinados acontecimientos o hechos históricos, tiene su traducción a nivel de lenguaje en un repertorio de fórmulas o imágenes que provienen del ornatus retórico, y que confieren a la laus una forma literaria o unas características peculiares, apropiadas bien porque han sido utilizadas tradicionalmente o bien porque ofrecen determinadas posibilidades al elogio: tropos, como metáforas, hipérboles, antonomasias o énfasis; figuras de pensamiento amplificativas, como amplificatio, expolitio, digresión, paréntesis; o acumulativas, como enumeración, distributio o epífrasis; figuras descriptivas, etopeya, topografía; de diálogo, exclamaciones, interrogaciones retóricas; y, por último, comparaciones y símiles. Todo este arsenal retórico forma parte también de una tradición y de

37. «Überbietung», forma acuñada por E.R. Curtius, 1976: 235. 
una unidad cultural, incluso ideológica, que nos permite valorar la visión del mundo barroco por parte de la bicefalia autoral.

Además del arte retórico, el rasgo lingüístico más destacable de los encomios es la serie de categorías gramaticales ponderativas al servicio de los retratados. En este ámbito exceden los sustantivos encomiásticos, bien simples, en series dobles, muy frecuentes, o triples; ya más infrecuentes, cuádruples («felicidad militar, valor bélico, sangre Marcial y ánimo hazañoso») o incluso múltiples («La cual señora, si bien se aventajaba a todas las mujeres de aquel siglo en hermosura, gentileza, bizarría, gala, discreción y gracia, en antigüedad, nobleza, lustre y valor de linaje, ninguna le era superior»). Esta técnica acumulativoelogiosa de términos gramaticales es uno de los paradigmas encomiásticos más utilizados y más visibles en una primera lectura. La adjetivación elogiosa también es muy repetida, tanto en conjuntos dobles, epítetos, superlativos o en series triples y hasta cuádruples («estimado, amado, honrado y alabado de todos»). En su aspecto léxico, los verbos introducen predicados elogiosos, a veces también en series, especialmente de conjuntos binarios («alaban y estiman»).

Es común también el uso de los estilos directo e indirecto, reproduciendo supuestas conversaciones. Esta es una técnica más que intenta reforzar la verosimilitud de la narratio, en función del arrojo o la sabiduría de los héroes; pero asimismo puede servir para acercarnos razonamientos variados, informativos o estrategias militares. En unas ocasiones, nos transcriben consideradas alabanzas de importantes personajes de la Corte, premiando acciones (reyes, príncipes, gobernadores, maeses de campo, mariscales...). En otras, se reproducen cartas, algunas fechadas, bien dirigidas a los encomiados con órdenes, consejos o felicitaciones, o de estos a sus superiores al estilo de las relaciones o memoriales de la Conquista, con los que guarda evidentes paralelismos, como ya hemos comentado. La combinación de estos dos estilos, uno más elevado, procedente del género, la tradición o la retórica, conviviendo con otro mayoritariamente coloquial, de ornatus moderado, define otra de las características de estilo.

También encontramos motivos tradicionales que son lugares comunes pertenecientes a la tradición tópica. Ya hemos citado sapientia et fortitudo, omnis sexus et aetas ('todos festejan al encomiado'), el sobrepujamiento, la nobleza del alma, la fama del individuo e incluso de la familia, que no conoce fronteras, o los dones con que la Naturaleza o la divinidad les distingue. Podríamos ańadir el hombre como navegante en busca de destino, fortuna o mérito; el de la naturaleza intrépida del individuo; el de las conclusiones a modo de reticencia dirigidas al lector para advertirle de las maravillas que deja de contar («Dejo finalmente otras mil cosas, que el menor dellos bastará a dar honra a una familia y hacerla perpetuamente ilustre y noble»). El tópico puer senex, muy del gusto en los encomios y que ya Claudiano empleaba en el panegírico de grandes personajes, presenta sobre todo la variante del joven o adolescente pleno de madurez y sabiduría, más propia del anciano (se inicia el capítulo del conde 
del Villardompardo: "Dende su primera edad dio muestras de su prudencia, porque en los años juveniles se gobernó con tal razón y discurso, que siempre dio esperanzas de lo que adelante se gozó en colmados frutos»; el adolescente Espinosa de los Monteros, una vez en la milicia «tenía modestia de mayor edad, palabras de experimentado, osadía de hombre animoso y valiente»). Se nota en estos casos, dada la relación con la técnica hagiográfica, la importancia de la figura de Cristo, como antecedente, para la creación de estos mitos creyentes, que también podían servir para suscitar la fe en los lectores.

Por último, el modo narrativo, a pesar de los recursos comentados hasta ahora, intenta seguir las cualidades de la narratio verisimilis como finalidad en la exposición, especialmente en los episodios históricos. Aquí es importante la voz del narrador, quien en sus relaciones parece ser testigo de vista, contando al detalle las diferentes hazañas, escaramuzas o viajes. Por otro lado, también se pueden advertir los principios de la doctrina contrarreformista, sobre todo por parte de un celoso guardián de Trento, como Patón ${ }^{38}$, a través de la importante presencia de Dios en los hombres y los hechos acontecidos. Si la religión podía convertirse en la época en un consuelo o en un freno, aquí opera como arma doctrinaria.

Volviendo al modo narrativo, las dos técnicas más repetidas en las descripciones epidícticas son: la de la acumulación de historias, como parte de la amplificatio elocutiva, con episodios algunos puramente anecdóticos, otros de base más o menos histórica y otros ordenados por virtudes, que da por momentos ese aire de relato de aventuras en los diferentes continentes. La segunda es la técnica digresiva (digressio) que, intercalada, interrumpe continuamente la narración (narratio partilis). La amplitud de estas depende de la historia o del concepto. Por regla general, las extensas son las que ocupan mayor espacio, pero también aparecen las encadenadas, en una especie de sucesión que a veces nos hace perder el hilo inicial. Destacan aquellas que proponen advertencias sermonísticas varias, edificantes, sobre el vicio, la virtud, la perfección, la condenación, la oración... tan características del piadoso Patón, regadas con ejemplos de clásicos como Juvenal, Marcial ${ }^{39}$, Estacio o las Escrituras. Al autor tampoco le pasan desapercibidas y, en varias ocasiones, nos hace cómplice de la técnica: «Dirasme a qué propósito es esta digresión. A propósito de que querría quedases advertido en lo que te conviene hacer en la elección de estado y modo de vivir, para que por la vida temporal no pierdas las causas de conseguir la eterna» (f. 122v). Y es aquí donde se introduce la parte doctrinaria, haciéndola coincidir con el panegírico. Así, si el primer propósito es encomiar a Jaén y a sus hijos ilustres, la ocasión también puede servir para suscitar la fe y advertir de sus peligros: «Porque si el fin de escribir la historia se

38. Los autores demuestran el conocimiento de las disposiciones conciliares en varias ocasiones: «... porque después del sagrado Concilio de Trento, están muy prohibidos estos desafíos con muy graves censuras» (fol. 124r).

39. Patón fue traductor y comentarista de estos dos clásicos en sus Declaraciones magistrales, por lo que seguramente esos fragmentos del libro pertenecen a su pluma. 
endereza a persuadir la virtud con el premio y gloria de los bienes y hacer que se aborrezca el vicio con la pena y castigo de los malos [...] ¿por qué no se me dará para advertir lo que importa?» (f. 123r).

\section{Bibliografía}

Becerra Hiraldo José Ma, 2009, «Escuelas de gramática y retórica del Siglo de Oro en la España Meridional», en Martínez González Antonio, Historia de las ideas lingüísticas. Gramáticos de la España meridional, Frankfurt am Main, Peter Lang, 2009, pp. 65-81.

Cerdan, Francis, 1985, «La oración fúnebre del Siglo de Oro: entre sermón evangélico y panegírico poético sobre fondo de teatro", Criticón, 30, 1985, pp. 78-102.

Curtius E.R., 1976, Literatura europea y Edad Media latina, Madrid, Fondo de Cultura Económica, 1976.

Domínguez Ortiz Antonio, 1963, La sociedad española en el siglo xvii. i. El estamento nobiliario, Madrid, CSIC, 1963.

Etreros Mercedes, 1983, La sátira politica en el siglo xvii, Madrid, FUE, 1983.

Jiménez Patón Bartolomé, 1621, Mercurius trimegistus, sive de triplici eloquentia sacra, española, romana, Baeza, Pedro de la Cuesta Gallo, 1621.

- 1635, Decente colocación de la Santa Cruz, Cuenca, Juan de la Iglesia, 1635.

- 1638, Discurso en favor del santo y loable estatuto de la limpieza, Granada, Andrés de Santiago Palomino, 1638.

- 1980, Elocuencia española en arte (1604), en La retórica en España, ed. Elena Casas, Madrid, Editora Nacional, 1980.

- 1983, Historia de la antigua y continuada nobleza de la ciudad de Jaén, muy famosa, muy noble y muy leal guarda y defendimiento de los Reinos de España. $Y$ de algunos varones famosos, hijos della, Jaén, Pedro de la Cuesta, 1628. Ed. facsímil de Rafael Ortega y Sagrista, Jaén, Riquelme y Vargas ediciones, 1983.

— 2010, Comentarios de erudición ("Libro decimosexto»), ed. crítica C. Bosch, J. Garau, A. Madroñal y J. M. Monterrubio, Madrid-Frankfurt am Main, IberoamericanaVervuert-CSIC, 2010.

- 2014, El virtuoso discreto. Primera y segunda parte (1629-1631), ed. J. Garau$M^{a}$ del Carmen Bosch, Madrid-Frankfurt am Main, Universidad de NavarraIberoamericana-Vervuert, $2014 \mathrm{~b}$.

— 2017, Discursos (de calamidades, cruces y herejes), ed. Juan C. González Maya, New York, IDEA, 2017.

Jovio Paulo, 1568, Elogios o vidas breves de los caballeros antiguos y modernos, ilustres en valor de guerra, que están al vivo pintados en el museo de Paulo Jovio, Granada, Hugo de Mena, 1568.

Madroñal Durán Abraham, 2009, Humanismo y filología en el Siglo de Oro. En torno a la obra de Bartolomé Jiménez Patón, Madrid-Frankfurt am Main, IberoamericanaVervuert, 2009.

- 2011, Sociedad, pobreza y moda en la España del Siglo de Oro (Según la obra última de Bartolomé Jiménez Patón), Madrid, Editorial Académica Española, 2011. 
Manchón Gómez, Pedro, 2008, Vida y obra de un aventurero que dio vuleta y media al mundo, Jaén, Universidad de Jaén, 2008.

Martínez de Mazas José, 1794, Retrato al natural de la ciudad y término de Jaén, Jaén, Pedro de Doblas, 1794.

Montuno Morente Vicente, 1945, «Estudio del humanista Bartolomé Jiménez Patón como historiador de Jaén", Paisaje, 13, 1945, pp. 345, 441-43, 731, 904-909.

Ordóñez de Ceballos Pedro, 1614, Cuarenta triunfos de la santísima Cruz de Cristo N.S. y Maestro, Madrid, Luis Sánchez, 1614.

- 1628, Tratado de las relaciones verdaderas de los reinos de la China, Cochinchina y Champaa y otras cosas notables, y varios sucesos sacados de sus originales, Jaén, Pedro de la Cuesta, 1628.

- 1957, 1993, Viaje del mundo. Hecho y compuesto por el licenciado Pedro Ordónez de Ceballos, Madrid, Luis Sánchez, 1614. Hay ediciones modernas de Juan Luis Alborg, Madrid, Aguilar, 1957 y Félix Muradás, Madrid, Miraguano-Polifemo, 1993.

Serrano y Sanz Manuel, 1905, Autobiografias y memorias, Madrid, NBAE 2, 1905.

Zugasti Miguel, 2003, «El "Viaje del mundo” (1614) de Pedro Ordóńez de Ceballos o cómo modelar una autobiografía épica», Iberomanía, 58, 2003, pp. 83-119. 